\title{
Clinical characteristics of COVID-19 in young patients differ from middle-aged and elderly patients
}

Keqiang Wan ${ }^{1}$, Chang Su${ }^{1}$, Lingxi Kong ${ }^{1}$, Juan Liao ${ }^{2}$, Wenguang Tian' ${ }^{1}$, Hua Luo ${ }^{3}$

${ }^{1}$ Department of Infectious Diseases, Yongchuan Hospital of Chongqing Medical University, Chongqing, China

${ }^{2}$ Central Laboratory, Yongchuan Hospital of Chongqing Medical University, Chongqing, China

${ }^{3}$ Department of Respiratory and Critical Care Medicine, YongChuan Hospital

of Chongqing Medical University, China

Submitted: 25 October 2020; Accepted: 5 February 2021

Online publication: 21 March 2021

Arch Med Sci 2022; 18 (3): 704-710

DOI: https://doi.org/10.5114/aoms/133090

Copyright $\odot 2022$ Termedia \& Banach

\section{Abstract}

Introduction: Coronavirus disease-2019 (COVID-19) has spread worldwide. The study aimed to understand the clinical characteristics of young COVID-19 patients.

Material and methods: Ninety patients with severe COVID-19 infection in western Chongqing were collected from 21 January to 14 March 2020. They were divided into 4 groups based on age: youth (<39 years), middle-aged (39-48 years), middle-elderly aged (49-60 years), and elderly (> 60 years). The clinical symptoms, laboratory findings, imaging findings, and treatment effects were compared among the groups.

Results: There were 22, 27, 19, and 22 cases in the youth, middle-aged, middle-elderly, and elderly groups, respectively. There were no significant differences with respect to gender or smoking status among the four groups. The clinical indicators of severe disease in the youth group were significantly different from the other three groups, and included the lymphocyte count $(p<0.001)$, C-reactive protein level $(p=0.03)$, interleukin-6 level $(p=0.01)$, chest computed tomography (CT) findings $(p<0.001)$, number of mild cases $(p=0.02)$, education level $(p<0.001)$, and CD4 + T lymphocyte level $(p=0.02)$ at the time of admission, and the pneumonia severity index (PSI) at the time of discharge $(p<0.001)$. The complications $(p<0.001)$ among the youth group were also significantly different from the other groups.

Conclusions: Young patients have milder clinical manifestations, which may be related to higher education level, higher awareness and higher acceptance of the prevention and control of the COVID-19 epidemic, as well as their good immune function.

Key words: COVID-19, western Chongqing, young patients, clinical characteristics.

\section{Introduction}

Since severe acute respiratory syndrome coronavirus 2 (SARS-CoV-2) was first discovered in Wuhan in December 2019, coronavirus disease-2019 (COVID-19) has spread worldwide. China has made great efforts to control this epidemic. Although more than 12 months has passed since the outbreak of COVID-19, the situation in some countries is not optimistic. A face mask is one of the key tools to protect medical staff in hospitals and clinics and plays an important role in reducing the spread of COVID-19 [1]. Efforts to fight COVID-19 are dual in nature and include

\author{
Corresponding author: \\ Hua Luo \\ Department of \\ Respiratory and \\ Critical Care Medicine \\ Yongchuan Hospital \\ of Chongqing Medical \\ University \\ Chongqing, China \\ E-mail: \\ LuoHua1380930@163.com
}


supply of vaccines and/or effective drugs to the market to prevent infection. Unrealistic optimism/ pessimism may be a key factor in the eradication of COVID-19 [2].

The psychological problems caused by COVID-19 infection cannot be ignored. A study reported that $10.8 \%$ of patients experience severe anxiety and depression and need psychological intervention to reduce psychological trauma [3]. Although we have gained some experience in preventing and treating COVID-19, our knowledge and research on COVID-19 are still limited because it is difficult to directly detect airborne viruses [4].

There is a correlation between the incidence of COVID-19 in children and adults that increases with the age of children. However, we currently underestimate the number of pediatric cases [5]. Indeed, elderly patients infected with COVID-19 have relatively severe clinical manifestations due to complications, while young patients with COVID-19 have mild symptoms and the number of critical cases is small. The specific reasons are not clear. COVID-19 may use angiotensin-converting enzyme 2 (ACE2) as a receptor to initiate infection, leading to severe complications from the heart, lungs, and gastrointestinal tract [6].

Yongchuan Hospital Affiliated to Chongqing Medical University is the designated hospital for COVID-19 patients in western Chongqing. As of 14 March 2020, a total of 90 patients had been admitted to the COVID-19 isolation ward. The clinical presentations and symptoms of COVID-19 vary in frequency and severity, and the symptoms differ with the severity of disease. The age-dependent susceptibility to COVID-19 (children are less likely to be infected than adults) results in a reduced number of cases in children. Kuchar et al. [7] reported that SARS-CoV-2 infections in children exhibiting COVID-19 symptoms and requiring hospitalization are significantly lower than in hospitalized adults. Indeed, the immune cross-protection of other coronaviruses may lead to reduced sensitivity [8, 9].

This study retrospectively analyzed the general conditions, clinical symptoms, laboratory test results, imaging findings, and treatment of the 90 patients from different age groups and examined the differences and regularities between young patients and middle-aged and elderly patients. We sought to establish valuable clinical evidence for the prevention and control of COVID-19.

\section{Material and methods}

\section{Patient data collection}

Yongchuan Hospital is a major tertiary teaching hospital. Yongchuan Hospital has an Infectious Diseases Department, is affiliated with Chongqing
Medical University, and is located in Yongchuan district, Chongqing City. Yongchuan Hospital is responsible for treating patients in eight regions and counties from Chongqing City. This study included 90 COVID-19 patients admitted to the hospital during the period from 21 January to 4 March 2020. All of the patients were diagnosed with COVID-19 at the time of admission by RT-PCR. The severity of disease was classified as mild or severe according to the Pneumonitis Diagnosis and Treatment Scheme for Novel Coronavirus Infection (Trial Version 6) [10].

\section{Research methods}

We collected data from all patients, including epidemiologic data, clinical manifestations, laboratory test results, imaging findings, and outcome. The patients were evaluated 6 months after hospital discharge. Epidemiologic data were consolidated from case studies and epidemiologic surveys were conducted by the local Centers for Disease Control and Prevention (CDC). The inclusion criteria were as follows: 1 . fever, cough, and a history of close contact with other patients. 2. throat or upper respiratory tract secretions shown to be positive for SARS-COV-2 by RT-PCR. 3. influenza $A$ and $B$, common respiratory virus, SARS-CoV, and MERS-CoV infections were ruled out.

Blood counts and biochemical tests were completed in the Department of Clinical Laboratory of our hospital and low-dose spiral computed tomography (CT) examinations of the chest was performed in the Radiology Department. All data were checked by two executors. In this retrospective study all data were shared with the Chongqing Municipal Health Commission. The patients ranged in age from 3 to 89 years, with an average age of $48 \pm 18$ years. According to the age interquartile range $(I Q R)$, the patients were divided into 4 groups: youth (< 39 years), middle-age (3948 years), middle-elderly (49-60 years), and elderly (> 60 years). The differences in clinical symptoms, laboratory test results, imaging findings, and treatment effects were compared among the four groups.

\section{Observation items}

Clinical symptoms, such as fever, non-productive and productive cough, fatigue, shortness of breath, myalgias, and diarrhea, and the laboratory test results, including routine blood tests, C-reaction protein (CRP) level, interleukin-6 (IL-6) level, blood coagulation profile, and lymphocyte subset counts, were collected. Pneumonia was diagnosed based on a low-dose 256 detector row CT of the chest and examined by two radiologists. The clinical discharge criteria for patients were based on 
the COVID-19 diagnosis and treatment protocol (trial version 6), as follows: 1) body temperature returned to normal for at least 3 days. 2) clinical symptoms of the respiratory tract were significantly improved. 3) re-examination of pulmonary imaging showed significant improvement of acute exudative lesions. 4) two consecutive negative nucleic acid tests of respiratory tract specimens (at least 1 day between sampling intervals) [10].

\section{Statistical analysis}

SPSS 26.0 statistical software was used for statistical analysis of the results, and a $p<0.05$ was considered statistically significant. Measurement data were expressed as the mean \pm standard deviation (SD). The Student-Newman-Keuls (SNK) method was used for intergroup comparisons following the one-way ANOVA analysis. Enumeration data were analyzed using the $\chi^{2}$ test.

\section{Results}

\section{General information}

There were 22 (24.4\%), 27 (30.0\%), 19 (21.2\%), and 22 patients $(24.4 \%)$ in the youth, middle-age, middle-elderly, and elderly groups, respectively.
The youth group accounted for 63.64\% (14/22) of the patients with a high school education or above, which was significantly different from the other 3 groups $(p<0.05)$. The incidence of complications in the youth group (4.55\%) was significantly lower than in the other 3 groups. There was no significant difference in the distribution of gender or smoking history in the 4 groups $(p>0.05$, Table I).

\section{Clinical symptoms}

The main clinical manifestations of COVID-19 patients included fever, non-productive and productive cough, fatigue, shortness of breath, myalgias, diarrhea, headaches, pharyngeal neuralgia, chills, and anorexia, as well as other types of discomfort in a small number of patients. The proportion of main clinical symptoms did not differ significantly among the four age groups $(p>0.05$, Table II).

\section{Laboratory findings}

On admission, 90 patients underwent hematologic, biochemical, and routine serology testing. There was no significant difference in the white blood cell count among the four groups $(p>0.05)$.

Table I. General information pertaining to the four groups of COVID-19 patients

\begin{tabular}{|c|c|c|c|c|c|c|}
\hline $\begin{array}{l}\text { General } \\
\text { information }\end{array}$ & $\begin{array}{c}\text { All } \\
(n=90)\end{array}$ & $\begin{array}{l}\text { Youth group } \\
\quad(n=22)\end{array}$ & $\begin{array}{c}\text { Middle-age } \\
\text { group }(n=27)\end{array}$ & $\begin{array}{l}\text { Middle-elderly } \\
\text { group }(n=19)\end{array}$ & $\begin{array}{l}\text { Elderly group } \\
\quad(n=22)\end{array}$ & $P$-value \\
\hline $\begin{array}{l}\text { Age [years] } \\
(\text { mean } \pm S D)\end{array}$ & $48 \pm 18$ & $25 \pm 11$ & $45 \pm 3^{a}$ & $53 \pm 3^{a / b}$ & $71 \pm 8^{\mathrm{a} / \mathrm{b} / \mathrm{c}}$ & $<0.05$ \\
\hline Male, $n(\%)$ & $52(57.8)$ & $15(68.18)$ & $13(48.15)$ & $11(57.89)$ & $13(59.09)$ & 0.57 \\
\hline $\begin{array}{l}\text { Smoking history, } \\
n(\%)\end{array}$ & $9(10)$ & $1(4.55)$ & $4(14.81)$ & $2(10.53)$ & $2(9.09)$ & 0.69 \\
\hline $\begin{array}{l}\text { High school } \\
\text { education or } \\
\text { above, } n(\%)\end{array}$ & 19 (21.59) & $14(63.64)$ & $2(7.69)^{a}$ & $2(10.53)^{a}$ & $1(4.55)^{\mathrm{a}}$ & $<0.05$ \\
\hline $\begin{array}{l}\text { Complications, } \\
n(\%)\end{array}$ & 35 (39.33) & $1(4.55)$ & $6(22.22)^{\mathrm{a}}$ & $12(63.16)^{a / b}$ & $16(72.73)^{a / b}$ & $<0.05$ \\
\hline
\end{tabular}

Table II. Main clinical symptoms of COVID-19 patients in the four groups

\begin{tabular}{|c|c|c|c|c|c|c|}
\hline $\begin{array}{l}\text { Main clinical } \\
\text { symptoms }\end{array}$ & $\begin{array}{c}\text { All } \\
(n=90)\end{array}$ & $\begin{array}{l}\text { Youth group } \\
\quad(n=22)\end{array}$ & $\begin{array}{c}\text { Middle-age } \\
\text { group }(n=27)\end{array}$ & $\begin{array}{l}\text { Middle-elderly } \\
\text { group }(n=19)\end{array}$ & $\begin{array}{l}\text { Elderly group } \\
\quad(n=n 22)\end{array}$ & $P$-value \\
\hline Fever, $n(\%)$ & $43(47.78)$ & $10(45.45)$ & $14(51.85)$ & $10(52.63)$ & $9(40.91)$ & 0.84 \\
\hline $\begin{array}{l}\text { Cough and } \\
\text { expectoration, } \\
n(\%)\end{array}$ & $55(61.11)$ & $12(54.55)$ & $12(44.44)$ & $14(73.68)$ & $17(77.27)$ & 0.07 \\
\hline Fatigue, $n(\%)$ & $20(22.22)$ & $8(36.36)$ & $5(18.52)$ & $3(15.79)$ & $4(18.18)$ & 0.33 \\
\hline $\begin{array}{l}\text { Shortness of } \\
\text { breath, } n(\%)\end{array}$ & $13(14.44)$ & $2(9.09)$ & $5(18.52)$ & $1(5.26)$ & $5(22.73)$ & 0.34 \\
\hline $\begin{array}{l}\text { Muscle } \\
\text { soreness, } n(\%)\end{array}$ & $7(7.78)$ & $1(4.55)$ & $2(7.41)$ & $1(5.26)$ & $3(13.64)$ & 0.67 \\
\hline Diarrhea, $n(\%)$ & $5(5.56)$ & $1(4.55)$ & $2(7.41)$ & $2(10.53)$ & $0(0)$ & 0.49 \\
\hline
\end{tabular}


Procalcitonin (PCT), an indicator of inflammation, did not differ significantly among the four groups $(p>0.05)$. Compared with the other three groups, the lymphocyte and CD4 + T counts of the youth group were significantly higher $(p<0.05)$, while the CRP and IL-6 levels were significantly lower $(p<0.05$, Table III).

\section{CT examination}

All patients had chest CT scans on admission, and the severity of acute lung exudative lesions was determined using the pneumonia severity index (PSI) [11]. Ninety percent (81/90) of the chest $\mathrm{CT}$ scans showed ground-glass opacities, patchy lesions, consolidation, cords, and network shadows. The number of patients without lesions in each group did not differ significantly among the four groups $(p>0.05)$. The PSI at the time of hospital admission and discharge in the middle-aged, middle-elderly, and elderly groups was significantly higher than in the youth group ( $p<0.05$, Table IV).

\section{Treatment}

Among the 90 patients, 77 (85.6\%) were mild, $13(14.4 \%)$ were severe, and the number of mild cases in the youth group accounted for $100 \%$. All patients received antiviral treatment. For patients with bacterial pneumonia, we used piperacillin-ta-

Table III. Laboratory findings for SARS-CoV-2-infected patients

\begin{tabular}{|c|c|c|c|c|c|}
\hline Laboratory test & All $(n=90)$ & $\begin{array}{l}\text { Youth group } \\
\quad(n=22)\end{array}$ & $\begin{array}{c}\text { Middle-age } \\
\text { group }(n=27)\end{array}$ & $\begin{array}{l}\text { Middle-elderly } \\
\text { group }(n=19)\end{array}$ & $\begin{array}{l}\text { Elderly group } \\
\qquad(n=22)\end{array}$ \\
\hline WBC $\left[\times 10^{9} / 1\right]$ & $5.44 \pm 2.25$ & $5.96 \pm 2.46$ & $5.84 \pm 2.63$ & $5.02 \pm 2.06$ & $4.78 \pm 1.42$ \\
\hline PCT [ng/ml] & $0.09 \pm 0.14$ & $0.11 \pm 0.23$ & $0.10 \pm 0.16$ & $0.09 \pm 0.06$ & $0.08 \pm 0.05$ \\
\hline $\mathrm{L}\left[\times 10^{9} / \mathrm{l}\right]$ & $1.22 \pm 0.58$ & $1.63 \pm 0.71$ & $1.10 \pm 0.47^{a}$ & $1.13 \pm 0.52^{\mathrm{a}}$ & $1.04 \pm 0.45^{a}$ \\
\hline Youth group $(n=22)$ & & & $p=0.005$ & $p=0.026$ & $p=0.003$ \\
\hline CRP $[\mathrm{mmol} / \mathrm{l}]$ & $18.12 \pm 24.12$ & $7.20 \pm 9.15$ & $16.70 \pm 26.57$ & $28.62 \pm 34.20^{\mathrm{a}}$ & $21.75 \pm 16.26$ \\
\hline Youth group $(n=22)$ & & & & $p=0.026$ & \\
\hline IL-6 [pg/ml] & $13.51 \pm 17.72$ & $6.35 \pm 7.58$ & $10.32 \pm 15.86^{a}$ & $14.51 \pm 15.10$ & $23.73 \pm 24.28^{\mathrm{a} / \mathrm{b}}$ \\
\hline Elderly group $(n=22)$ & & $p=0.005$ & $p=0.040$ & & \\
\hline $\begin{array}{l}\text { CD4+ T lymphocyte } \\
\text { count [per } \mu l]\end{array}$ & $494.43 \pm 279.30$ & $631.41 \pm 317.62$ & $457.22 \pm 241.66$ & $514.42 \pm 311.30$ & $385.86 \pm 200.49^{a}$ \\
\hline Youth group $(n=22)$ & & & & & $p=0.020$ \\
\hline
\end{tabular}

WBC - white blood cells, $P C T$ - procalcitonin, CRP - C-reaction protein, IL-6 - interleukin-6 (IL-6), ${ }^{a} p<0.05$ compared to the youth group; ${ }^{b} p<0.05$ compared to the middle-age group.

Table IV. CT results of 90 SARS-CoV-2-infected patients

\begin{tabular}{|lcccccc|}
\hline CT examination & $\begin{array}{c}\text { All } \\
(n=90)\end{array}$ & $\begin{array}{c}\text { Youth group } \\
(n=22)\end{array}$ & $\begin{array}{c}\text { Middle-age } \\
\text { group }(n=27)\end{array}$ & $\begin{array}{c}\text { Middle-elderly } \\
\text { group }(n=19)\end{array}$ & $\begin{array}{c}\text { Elderly group } \\
(n=22)\end{array}$ & $P$-value \\
\hline $\begin{array}{l}\text { No. of lesions, } \\
n(\%)\end{array}$ & $9(10.0)$ & $6(27.27)$ & $0(0)$ & $2(10.53)$ & $1(4.55)$ & 0.38 \\
\hline PSI on admission & $32.44 \pm 21.74$ & $8.13 \pm 4.73$ & $24.12 \pm 17.59^{\mathrm{a}}$ & $36.25 \pm 15.47^{\mathrm{a}}$ & $52.50 \pm 21.15^{\mathrm{a} / \mathrm{b}}$ & $<0.05$ \\
\hline PSI at discharge & $21.71 \pm 18.52$ & $9.64 \pm 12.53$ & $21.92 \pm 17.65^{\mathrm{a}}$ & $26.05 \pm 17.68^{\mathrm{a}}$ & $29.20 \pm 20.26^{\mathrm{a}}$ & 0.00 \\
\hline
\end{tabular}

${ }^{a} P<0.05$ compared to the youth group; ${ }^{b} p<0.05$ compared to the middle-age group.

Table V. Treatment scheme for a patient infected with COVID-19

\begin{tabular}{|c|c|c|c|c|c|c|}
\hline Treatment & $\begin{array}{c}\text { All } \\
(n=90)\end{array}$ & $\begin{array}{l}\text { Youth group } \\
\quad(n=22)\end{array}$ & $\begin{array}{c}\text { Middle-age } \\
\text { group }(n=27)\end{array}$ & $\begin{array}{l}\text { Middle-elderly } \\
\text { group }(n=19)\end{array}$ & $\begin{array}{l}\text { Elderly group } \\
\quad(n=22)\end{array}$ & $P$-value \\
\hline Antibiotics, $n(\%)$ & $32(35.56)$ & $6(27.27)$ & $8(29.63)$ & $8(42.11)$ & $10(45.45)$ & 0.50 \\
\hline $\begin{array}{l}\text { Methylprednisolone } \\
\text { therapy, } n(\%)\end{array}$ & $25(27.78)$ & $3(13.64)$ & $6(22.22)$ & $6(31.58)$ & $10(45.45)$ & 0.10 \\
\hline $\begin{array}{l}\text { Gamma globulin, } \\
n(\%)\end{array}$ & $13(14.44)$ & $1(4.55)$ & $5(18.52)$ & $3(15.79)$ & $4(18.18)$ & 0.50 \\
\hline $\begin{array}{l}\text { Ventilator-assisted } \\
\text { ventilation, } n(\%)\end{array}$ & $8(8.89)$ & 0 & $3(11.11)^{a}$ & 0 & $5(22.73)^{a}$ & 0.02 \\
\hline Mild cases, $n(\%)$ & 77 (85.56) & $22(100)$ & $23(85.19)^{\mathrm{a}}$ & $17(89.47)^{a}$ & $15(68.18)^{a}$ & 0.02 \\
\hline
\end{tabular}


zobactam treatment through an intravenous drip (4.5 g every $8 \mathrm{~h}$ ). For patients with gradual deterioration of the oxygenation index, rapid progression based on imaging findings, and excessive activation of the inflammatory response, methylprednisolone was administered at a dose of 1-2 $\mathrm{mg} / \mathrm{kg} /$ day for 3-5 days. The antibiotic and hormone treatment plans were adjusted according to the patient's condition. Among the 90 patients, 32 (35.6\%) received antibiotic therapy, 25 (27.8\%) received hormone (methylprednisolone) therapy, $13(14.4 \%)$ received gamma globulin therapy, and $8(8.9 \%)$ received ventilator-assisted ventilation (Table V). No patients in the youth group were mechanically ventilated, which was statistically different from the middle-aged and elderly groups $(p<0.05)$. There was no difference in the use of antibiotics, hormones, or gamma globulin between groups $(p>0.05)$.

\section{Discussion}

Adolescents and young adults are more often involved in social activities, communication and learning, and finding stable jobs, which increases susceptibility to the worldwide spread of COVID-19. Thus, public health officials should pay more attention to young patients infected with COVID-19. In the course of treatment, we found that the clinical manifestations of patients differed as a function of age. Young patients have mild symptoms and elderly patients have severe clinical manifestations, which are consistent with reports in the literature. Liao et al. [12] also found that the majority of young patients with COVID-19 infections were asymptomatic, rarely had critical conditions, and most had better prognosis and outcomes after treatment. The specific reasons for this were not further analyzed by the authors, and our study suggests that one of the possible reasons is the existence of complications of underlying diseases in middle-aged and elderly patients $[13,14]$. To date, the specific causes of mild clinical manifestations in young patients have not been reported. For other respiratory viral infections, including SARS, age-dependent differences in severity have been observed. For COVID-19, there are strong indications that the reported cases have age-dependent severity and mortality rates, which may extend to the possibility of clinically reportable symptoms after infection [15-17].

In this study, the ages of the 90 patients were stratified by interquartile spacing, and there was no significant difference in the number of cases among the four groups with respect to age and gender. The clinical characteristics of patients infected with SARS-CoV-2 were different among the four age groups. We observed that the main clinical symptoms of the four groups were fever, non-productive and productive cough, fatigue, and shortness of breath. In fact, there was no significant difference in the number of patients with the main clinical symptoms between the youth group and the other three groups. However, we observed significant differences in the PSI at the time of hospital admission and discharge between the youth and other three groups, which was consistent with previous reports [18-20].

Nine retrospective studies (1332 cases) were included. The results demonstrated that the combined proportions of findings were as follows: ground-glass opacities (GGOs), 0.79 (95\% Cl: 0.68$0.89)$; consolidation, 0.34 (95\% Cl: $0.23-0.47)$, combined GGOs and consolidation, $0.46(95 \% \mathrm{Cl}$ : 0.37-56); air bronchogram sign, $0.41(95 \% \mathrm{Cl}$ : 0.26-0.55); crazy paving pattern, $0.32(95 \% \mathrm{Cl}$ : 0.17-0.47); interlobular septal thickening, 0.55 (95\% Cl: 0.42-0.67); reticulation, $0.30(95 \% \mathrm{Cl}$ : 0.12-0.48); bronchial wall thickening, 0.24 (95\% Cl: 0.11-0.40); vascular enlargement, 0.74 (95\% Cl: 0.64-0.86); subpleural linear opacities, 0.28 (95\% Cl: 0.12-0.48); intrathoracic lymph node enlargement, 0.03 (95\% Cl: 0.00-0.07); and pleural effusions, 0.03 ( $95 \% \mathrm{Cl}$ : 0.02-0.06).

The distribution was characterized as peripheral, bilateral, and $>2$ lobes involved. Therefore, based on the above-mentioned chest CT features of COVID-19, chest CT should be considered a promising method for identifying COVID-19 [21].

The laboratory test findings showed significant changes in lymphocyte counts and CRP and IL-6 levels in the youth group, indicating that young patients were unlikely to develop severe disease $[22,23]$. This finding was attributed to underlying health issues in the elderly population, such as more co-morbidities, immunosenescence, decreased immune function, poor nutritional state, and increased frailty. Specifically, diabetes, heart disease, and other chronic illnesses can lead to more severe symptoms and complications in patients infected with COVID-19. Additionally, as people age, the immune system gradually loses its resiliency; thus patients are more susceptible to infections of any kind, especially a novel pathogen like COVID-19, while young people with robust immune function are less susceptible to SARS-CoV-2 [24].

Diabetes patients with COVID-19 have the worst prognosis because diabetes is characterized by low-grade chronic inflammation caused by excessive visceral adipose tissue. Chronic inflammation combined with hyperglycemia can lead to abnormal and ineffective immune responses. In addition, diabetes often co-exists with hypertension, and treatment with ACE inhibitors or angiotensin receptor blockers (ARB) may have harmful effects on patients with diabetes and COVID-19 [25].

During aging, the immune system changes in two main ways: there is a gradual decline in im- 
mune function (immunosenescence), and another classic immune system change during aging is a chronic increase in systemic inflammation (inflammaging), which is caused by an overactive but ineffective alert system [26]. A large amount of the most recent data on the pathologic and molecular changes of COVID-19 patients shows that immunosenescence and inflammaging are the main driving forces for the high mortality rate in elderly patients [27]. However, a comparative study of patients with moderate and severe disease found that gender and age are not risk factors for severe illness, but rather a combination of underlying factors, such as respiratory rate, lymphocyte count, blood glucose, albumin, urea, CRP, and IL-6 levels, and imaging findings [28].

We observed that the number of severe cases in the younger group was very low. Indeed, none of the youth in the current study had respiratory failure or required a ventilator to assist with respiratory support. The clinical characteristics of young patients are mostly mild with the following two important characteristics: the youth group included highly educated people with fixed professional and social identities, and the group used news media, the internet, new media platforms, and other media to enable them to recognize and understand COVID-19 earlier than other age groups. For those patients who have permanent work or a designated place of study, the range of activities may have been restricted, thus making it difficult to maintain close contact with COVID-19 patients. Second, the CD4+ T lymphocyte counts of the youth group were significantly higher than the other three groups at the time of hospital admission, indicating that this group has good cellular immune function.

It has been reported that the antibody levels in patients with mild clinical manifestations undergo rapid regression [29]. Fighting against SARS-CoV-2 does not depend on how many antibodies there are or how long the antibodies exist in the human body, but on the ability to mobilize the immune system quickly and effectively.

The lymphocyte counts in COVID-19 patients gradually decrease with progression of the disease, but the mechanism underlying the massive decrease in lymphocyte count in patients with severe disease is unclear [30]. As the disease progresses, the absolute number of CD8 + $T$ and NK cells is significantly reduced, but the cell sub-populations are highly activated. After the patient's condition improves, the number of CD8 + T and NK cells and the immune status recover to a certain extent [31]. Helper T lymphocytes are responsible for coordinating the entire immune response process, including assisting $B$ cells to produce antibodies and assisting NK cells to perform immune functions [32, 33]. Therefore, in young people, SARS-CoV-2 infection seems to be effectively controlled by good cellular immune function, thus manifesting as asymptomatic or mildly symptomatic infections. However, in order to further confirm these findings, it is necessary for future research to compare the severity of illness of COVID-19 patients with low education in the same age group.

In conclusion, among young patients, a higher level of education, higher awareness, and a high degree of acceptance of COVID-19 epidemic prevention and control may reduce the chance of exposure to SARS-CoV-2. Moreover, the youth group has good immune function, and can effectively control the virus. Thus, young patients infected with SARS-CoV-2 showed mild clinical manifestations. Therefore, we should not only strengthen the publicity and education about COVID-19, but also strengthen our physical fitness and design and develop a vaccine that can fully stimulate the immune system to control SARS-CoV-2 infection.

\section{Acknowledgments}

The authors would like to thank Liao Juan, a researcher from Yongchuan Hospital affiliated with Chongqing Medical University, for her guidance on the statistical methods in the manuscript, and thanks to Professor Tian Wenguang from Yongchuan Hospital affiliated with Chongqing Medical University for revising the manuscript! We would like to thank the Science and Technology Bureau of Yongchuan District, Chongqing for financial support of the research. Lastly, sincere appreciation is extended to all novel coronavirus prevention and control personnel on the front line.

\section{Conflict of interest}

The authors declare no conflict of interest.

\section{References}

1. Scarano A, Inchingolo F, Lorusso F. Facial skin temperature and discomfort when wearing protective face masks: Thermal infrared imaging evaluation and hands moving the mask. Int J Environ Res Public Health 2020; 17: 4624.

2. Kulesza W, Doliński D, Muniak P, et al. We are infected with the new, mutated virus UO-COVID-19. Arch Med Sci 2021; 17: 1706-15.

3. Liu C, Huang Q, Wang P, et al. COVID-19 disease: novel clinical manifestations and therapeutic exploration. Arch Med Sci 2020; doi:10.5114/aoms.2020.98401.

4. Morawska L, Cao J. Airborne transmission of SARSCoV-2: the world should face the reality. Environ Int 2020; 139: 105730.

5. Jackowska T, Wrotek A, Jankowski M, et al. Significant COVID-19 burden in Polish children. Arch Med Sci 2020; doi:10.5114/aoms.2020.98407.

6. Katsiki N, Banach M, Mikhailidis D. Lipid-lowering therapy and renin-angiotensin-aldosterone system inhibi- 
tors in the era of the COVID-19 pandemic. Arch Med Sci 2020; 16: 485-9.

7. Kuchar E, Załęski A, Wronowski M, et al. Children were less frequently infected with SARS-CoV-2 than adults during 2020 COVID-19 pandemic in Warsaw, Poland. Eur J Clin Microbiol Infect Dis 2021; 40: 541-7.

8. Nickbakhsh S, Ho A, Marques DFP, et al. Epidemiology of seasonal coronaviruses: establishing the context for the emergence of coronavirus disease 2019. J Infect Dis 2020; 222: 17-25.

9. Kissler SM, Tedijanto C, Goldstein E, et al. Projecting the transmission dynamics of SARS-CoV-2 through the postpandemic period. Science 2020; 368: 860-8.

10. China National Health Commission. Pneumonitis Diagnosis and Treatment Scheme for Novel Coronavirus Infection (Trial Version 6). Feb 18, 2020.

11. Satici C, Demirkol MA, Sargin AE, et al. Performance of pneumonia severity index and CURB-65 in predicting 30-day mortality in patients with COVID-19. Int J Infect Dis 2020; 98: 84-9.

12. Liao JQ, Fan SB, Chen J, et al. Epidemiological and clinical characteristics of COVID-19 in adolescents and young adults. Innovation 2020; doi :10.1016/j.xinn.2020.04.001.

13. Nanda A, Vura NVRK, Gravenstein S. COVID-19 in older adults. Aging Clin Exp Res 2020; 32: 1199-202.

14. Kang Y, Chen T, Mui D, et al. Cardiovascular manifestations and treatment considerations in COVID-19. Heart 2020; 106: 1132-41.

15. Galanti M, Birger R, Ud-Dean M, et al. Rates of asymptomatic respiratory virus infection across age groups. Epidemiol Infect 2019; 147: e176.

16. Zhou F, Yu T, Du R, et al. Clinical course and risk factors for mortality of adult inpatients with COVID-19 in Wuhan, China: a retrospective cohort study. Lancet 2020; 395: 1054-62

17. Riccardo F, Ajelli M, Andrianou X, et al. Epidemiological characteristics of COVID-19 cases in Italy and estimates of the reproductive numbers one month into the epidemic. medRxiv 2020; 04.08.20056861; doi: rg/10.1101/2020.04.08.20056861.

18. Xia W, Shao J, Guo Y, et al. Clinical and CT features in pediatric patients with COVID-19 infection: different points from adults. Pediatr Pulmonol 2020; 55: 1169-74.

19. Liu K, Chen Y, Lin R, et al. Clinical features of COVID-19 in elderly patients: a comparison with young and middle-aged patients. J Infect 2020; 80: e14-8.

20. Hui DS, I Azhar E, Madani TA, et al. The continuing 2019 nCoV epidemic threat of novel coronaviruses to global health - the latest 2019 novel coronavirus outbreak in Wuhan, China. Int J Infect Dis 2020; 91: 264-6.

21. Yang $H$, Lan Y, Yao X, et al. The chest CT features of coronavirus disease 2019 (COVID-19) in China: a meta-analysis of 19 retrospective studies. Virol J 2020; 17: 159.

22. Kanne JP. Chest CT findings in 2019 novel coronavirus (2019-nCoV) infections from Wuhan, China: key points for the radiologist. Radiology 2020; 295: 16-7.

23. Song F, Shi N, Shan F, et al. Emerging 2019 novel coronavirus (2019-nCoV) pneumonia. Radiology 2020; 295 210-7.

24. Wei C, Liu Y, Liu Y, et al. Clinical characteristics and manifestations in older patients with COVID-19. BMC Geriatr 2020; 20: 395.

25. Papazafiropoulou AK, Antonopoulos S. The COVID-19 pandemic and diabetes mellitus. Arch Med Sci Atheroscler Dis 2020; 5: e200-5.
26. Franceschi C, Bonafè M, Valensin S, et al. An evolutionary perspective on immunosenescence. Ann NY Acad Sci 2000; 908: 244-54.

27. Mueller AL, McNamara MS, Sinclair DA. Why does COVID-19 disproportionately affect older people? Aging (Albany NY) 2020; 12: 9959-81.

28. Li D, Liu C, Liu J, et al. Analysis of risk factors for 24 patients with COVID-19 developing from moderate to severe condition. Front Cell Infect Microbiol 2020; 10 548582.

29. Ibarrondo FJ, Fulcher JA, Goodman-Meza D, et al. Rapid decay of anti-SARS-CoV-2 antibodies in persons with mild covid-19. N Engl J Med 2020; 383: 1085-7.

30. Lin L, Lu L, Cao W, et al. Hypothesis for potential pathogenesis of SARS-CoV-2 infection-a review of immune changes in patients with viral pneumonia. Emerg Microbes Infect 2020; 9: 727-32.

31. Jiang Y, Wei X, Guan J, et al. COVID-19 pneumonia: CD8+ $\mathrm{T}$ and NK cells are decreased in number but compensatory increased in cytotoxic potential. Clin Immunol 2020; 218: 108516.

32. Tay MZ, Poh CM, Rénia L, et al. The trinity of COVID-19: immunity, inflammation and intervention. Nat Rev Immunol 2020; 20: 363-74.

33. Vabret N, Britton GJ, Gruber C, et al.; Sinai Immunology Review Project. Immunology of COVID-19: current state of the science. Immunity 2020; 52: 910-41. 